\title{
Miguelito lo dijo
}

Aquiles Montoyo

Ya habían transcurrido siete días desde el primer terremoto, cuando en el hospital de maternidad nació Miguelito. Fue el nacimiento número 666. La noticia de su natalicio se regó cual incendio en pradera veraniega azotada por el viento. Todo el mundo hablaba de su existencia y de sus características. Así como de su mensaje al nacer.

Miguelito nació con la piel arrugada, en verdad no parecía un bebé, sino un ancianito que se había ido encogiendo por el paso de los años. Tenía dientes y el pelo cano. Y al nomás abrir los ojos, como quien despierta de una larga pesadilla, manifestó:

"Siete males ha dispuesto Jehová para nuestro pueblo. El tiene la esperanza de que se ablande el corazón de piedra de los ricos y tengan por fin misericordia de los pobres. Pero de no ser así, todos pereceremos luego de sufrir larga y amargamente."

Ese fue el mensaje de Miguelito. No dijo ni una palabra mas. Luego de haber hablado, volvió a dormir. Eso parecía en un principio, pero la verdad es que yacía muerto en el lecho matemo. Y ella, su madre, respiró tranquila, porque nadie había visto, lo que ella contempló con terror en la nuca de su hijo, claramente dibujada estaba la cifra cabalística: 666 .

Todo lo que se dijo después son puras invenciones de la gente. El inago Manci, fue el primero que intentó descifrar el claro mensaje de Miguelito y haciendo cuentas no muy claras, luego de consultar la posición de los astros, declaró: De los siete males, ya padecimos, al menos tres, el dengue hemorrágico, el rota virus y el terremoto. Lo que nos falta, hasta donde yo alcanzo a leer, es otro terremoto, un maremoto, la erupción de uno o dos volcanes y el hundimiento de parte de Centro América. 
Muchos pastores de distintas iglesias hablaban del fin del mundo y llamaban a la conversión de los pecadores. Quizá eran los únicos que habían comprendido, aunque de manera parcial, el mensaje de Miguelito.

Cuando un mes después del primer terremoto se vino el segundo, todos comenzaron a creer lo dicho por el mago Manci. El litoral salvadoreño quedó desierto. La calle al puerto era la calle más desolada del país. Todos temían al anunciado maremoto y los últimos en salir de la costa, contaban que el mar había reculado como agarrando impulso para después venirse con toda su fuerza y la furia divina.

Los curas de los pueblos anunciaban, por los altoparlantes de las iglesias que habían quedado en pie luego del primer terremoto, que en el cerro de San Jacinto, próximo a la capital, se escuchaban retumbos y que se tuviera prudencia. Que lo mejor sería evitar cualquier viaje innecesario a San Salvador. La actividad comercial de la gran urbe decayó de golpe y porrazo. Es claro, que al millón de damnificados que ya existían, se unieron los privilegiados que aún no conocían de la desgracia de ver sus casas destruidas, a sus hijos con hambre y frío y de padecer la inexistencia de energía eléctrica y de agua potable.

El Gobierno de la República acosado por las demandas de los comerciantes que llevaban varios días sin vender nada, llamó a varios sismólogos norteamericanos para que vinieran a calmar a la población. El gobierno municipal, ante la espantosa caída en la recolección de impuestos se alarmó y buscó apoyar los esfuerzos del gobierno central, contratando a expertos geólogos españoles para que dijeran la verdad científica a la gente.

El arzobispo de San Salvador emitió su primera carta pastoral, donde recriminaba la actitud alarmista de los curas de los pueblos, se burló y excomulgó de una vez, a los magos como Manci, a quienes acusó de prácticas satánicas. Hizo un llamado a la calma y a la solidaridad con los desvalidos. Pero nada dijo del mensaje de Miguelito, tal parece que él entendía los designios del Altísimo, pero no se atrevió a hacer un llamado a la conversión de los ricos para no parecerse a los pastores de las Iglesias históricas y evitar el oportunismo político de los ortodoxos del Frente.

El pueblo que ya no creía en los políticos, fueran gobiemistas o de la oposición, como tampoco en la jerarquía católica, fiel defensora de los ricos, tenía serias y profundas sospechas de que no se le decía toda la verdad de lo que estaba ocurriendo. El pueblo pueblo, atendiendo más a los llamados de su conciencia, que a los de la ciencia, decidió organizar cadenas nacionales de oración y hermanarse con todos los creyentes, fueran de la confesión que fueran. Al fin y al cabo, sólo Dios podía salvarlos. Sólo Dios podía perdonar sus pecados.

A los miles de creyentes, las cosas parecían irles bien con las cadenas de oración al anochecer, las réplicas habían disminuido y la paz parecía volver de 
nuevo a los hogares, desafortunadamente para ellos, no creían en que pudiera ablandarse el corazón de piedra de los ricos y no pedían por su conversión, cuando ocurrió el tercer terremoto. Aquello fue el acabose.

Manci, que se había convertido en el profeta del Apocalipsis, seguido por miles y miles de mujeres, niños, ancianos y hombres, creyendo en sus propias palabras y habiendo descubierto que él era el padre de Miguelito, confesión que le hizo la madre — seguramente para lograr alguna ayuda del actual hombre más poderoso del país. Decidió convocar a todo el mundo a la cúspide del cerro de San Jacinto para, mediante un ayuno y oración de siete días y siete noches, conjurar el maleficio de aquel cerro y evitar que se siguiera cumpliendo la profecía de Miguelito, mediante el ablandamiento del corazón de piedra de los ricos.

La madre de Miguelito le había manifestado a Manci que durante siete meses estuvo siendo poseída mientras dormía por un ente incorpóreo y que nunca logró identificar de quién se trataba. Y que fue hasta que lo vio a él en la tele que pudo darse cuenta de que se trataba del mismo hombre que la poseía en sus sueños. Que seguramente en los viajes astrales que realizaba el telépata, medium y adivino era que la visitaba a ella, humilde mortal, en su lecho de virgen.

En el interior del país las cosas iban de mal en peor, a este momento y luego de tres sismos, —dos en fecha 13 y uno en 17, pero que al sumar 3 más 3 más 7 de los dos primeros y el tercero, también sumaba 13- los damnificados alcanzaban al $60 \%$ de la población, el hambre y la sed era imposible de satisfacer con las ayudas nacionales e internacionales. Una epidemia de cólera se había extendido a nivel nacional. En todas partes se veían señales de nuevos desastres: los volcanes inactivos echaban humo, los cerros retumbaban, la luna estaba creciendo demasiado como si se aproximara cada noche a la tierra. Los lagos elevaban sus niveles de agua, mientras los ríos se secaban y las mareas cada vez se veían más lejanas como si el mar estuviera retrocediendo. El agua de los chorros caía lodosa y por las noches se escuchaban alaridos de cerdos y aullidos de perros. Los gallos ya no cantaban al amanecer y las gallinas dejaron de poner huevos.

Las carreteras se habían vuelto intransitables, no sólo por las muchísimas grietas que las surcaban, sino por los miles de hambrientos que asaltaban a cualquier vehículo que se aventurara recorrerlas. Los viajeros eran despojados de cualquier cosa que llevaran, ya fuera de comer, de vestir, de beber o de valor. En algunos casos hasta los radiadores de los vehículos eran abiertos para sacarles la poca de agua hirviendo que poseían. Algunos ricos que se opusieron a colaborar voluntariamente fueron asesinados por turbas enajenadas por el hambre y la sed. Y aún así su corazón no se ablandaba, quizá, hasta más se endurecía.

Los canales de televisión ya no transmitían noticias del desastre para evitar alarmar a la poca población que quedaba, ya que muchos salvadoreños habían emigrado a los EE UU, los primeros fueron los del Comité de Emergencia Nacio- 
nal y los empresarios de CONASOL, junto al arzobispo de San Salvador, el Nuncio y el Presidente de la República con todo su gabinete, aunque éstos manifestaron que iban en una gira a buscar ayuda intemacional. La cúpula de los renovadores se fue acompañando al presidente y a su gabinete. Algunos ortodoxos se estaban convirtiendo a la fe, se les veía en reuniones con los bautistas y luteranos, sostenían los farabundistas que éstos si eran consecuentes.

Sólo existía un noticiero que seguía transmitiendo, a pesar de haber sufrido su director tres atentados de los que logró salir con vida de puro milagro. Este joven periodista, buscaba a base de razonamientos científicos y pruebas documentales, desenmascarar la charlatanería del mago Manci y la inoperancia del gobierno, pero la población que quedaba ya no lo miraba. Pensaban que estaba loco o bien, en contubernio con los ateos del Frente.

Las multitudes habían cubierto totalmente el cerro de San Jacinto. Desde cualquier lugar de la capital se veía aquella inmensa masa de mortales ayunando y rezando. Se encontraban ya en el séptimo día. Las emisoras de radio transmitían en directo los rezos y desde los refugios los salvadoreños que habían quedado, repetían las rogativas dirigidas por el mago Manci.

De repente a las doce en punto del séptimo día de oración y ayuno, el piso del cerro de San Jacinto colapsó en su parte superior y con gran estruendo se tragó a Manci y a cientos de miles de sus seguidores. Luego salió una inmensa y gigantesca columna de humo que se elevó por los cielos y fue vista hasta por uno de los satélites espías de los EE UU, igual se la vio en Guatemala, México, Honduras, Nicaragua, Costa Rica y Panamá. Después del humo, vino el fuego y la ceniza. Cien kilómetros a la redonda del cerro de San Jacinto quedaron destruidos por el fuego voraz que todo lo consumía: vegetación, animales, casas, vehículos y personas.

Entre los pocos sobrevivientes del holocausto se encuentra un viejo marxista, radicado en Catacamas, Honduras y dedicado ahora, después de muchos años de ocurrido el evento, a contar historias a quien quiera escucharlo. En esta ocasión se entretiene con sus pequeños vecinos, relatándoles la historia de Miguelito, la cual concluyó con estas palabras:

Ahora de El Salvador no queda nada. Y con algo de rabia agregó: ¡Puta, y ni aún así, no se ablandó el corazón de piedra de los ricos!

Aunque en sus adentros pensó: Pero es que no podía ser de otra manera, ya que el sistema es así. 